\title{
The Influence of Job Satisfaction, Workplace Learning on Nursing Performance Among Clinical Nurses
}

\author{
Ji-Hye Jang ${ }^{1}$, Myeong-Soon Jung ${ }^{2}$, Ga-Yeon $\mathrm{Ko}^{3}$, Eun-Jin Soun ${ }^{4}$ and \\ Young-Soon $\mathrm{Choi}^{5}$ \\ ${ }^{1,2,3}$ Dept. of Nursing, Gangneung YeongDong Univ., 357 Gongiero, Gangneung, \\ Korea \\ ${ }^{4}$ Dept. of Nursing, Hallym University, Chuncheon Sungsim Hospital, Chuncheon, \\ Korea \\ ${ }^{5}$ Dept. of Nursing, Kangwon National Univ., Samcheck, Korea \\ ${ }^{1}$ gogh0049@gmail.com, ${ }^{5} y s c 615 @$ hanmail.net
}

\begin{abstract}
This study was conducted as a descriptive research study to confirm the workplace learning, job satisfaction, and nursing work performance of nurses. The data collection period was October, 2016, and a total of 155 questionnaires were analyzed. Nurses' workplace learning averaged 3.97 points on a 6-point scale, job satisfaction was 2.99 on a 5 point scale, and nursing performance was 3.70 on a 5-point scale. There was a significant difference in job satisfaction according to working department and work type, and there was a significant difference according to education level, marital status, department, and type of work. The results of this study are significant in confirming the influencing factors of the workplace learning in the nursing field.
\end{abstract}

Keywords: Workplace, Learning, Job, Satisfaction, Nursing, Performance

\section{Introduction}

A human being and an organization grow through learning. Learning in the organization is the origin of knowledge creation and is a primary means of securing the organization competitive power [1]. Most organizations offer educational training to organizational members, thereby promoting the improvement in individual capability. An individual's enhanced capacity is being expected to lead likely to organizational performance. For this, the focus is being put on developing environment in which organizational members' continuous learning can be made. This is because of believing that the more occurrence in learning leads to being improved the ability in an individual and an organization of coping flexibly with an environmental change [2].

As a hospital is a place that is integrated a variety of advanced medical technologies and medical equipment as well as manpower such as a nurse, a doctor and a medical technician, the recent medical environment is rapidly changing owing to a change in internal and external conditions. Also, even consumers' needs are being advanced and diversified. Thus, to counteract this environmental change flexibly and effectively, an attention is being increased to the development in a nurse's competence and nursing performance in the hospital [3].

Article history:

Received (October 24, 2017), Review Result (November 29, 2017), Accepted (January 10, 2018) 
Beyond the limit of a place, a work site is a place that is happened the work-related learning, the learning through work, and the work-based learning through utilizing work itself as a topic, an objective, a method and a material of the learning [4].

As workplace learning implies the learning at work that takes place in a work site, it is the process of acquiring capability necessary for job performance through the learning experience that an individual of belonging to an organization obtained amidst an interaction with many people in the workplace environment and organization [5]. A type of workplace learning is being contended variously by each of the scholars. But the workplace learning is divided into formal learning, informal learning, and incidental learning [5]. The formal learning is what is planned and specific that is made in order to guide a method of performing a specific job. The informal learning is what happens through a demonstrative presentation in a situation that the learning process is not fixed in advance. The incidental learning is the one that is created by an unintended by-product according to any activity like interpersonal interaction or trial and error [5][6].

Job satisfaction implies a satisfaction level of being felt according to a desire or a value of being possessed by an individual, namely, the delightfulness or good emotional state that an individual comes to obtain through evaluating job [7], and was defined as a pleasant and positive emotional state that each individual of the members feel through job [8]. In addition, as job satisfaction is mentioned to be 'what is an emotional state related to job, this is what is individually varied depending on a level in an individual's attitude, value, faith and desire.' It was reported that the affirmative emotion of task life has an effect on organization operation and job satisfaction, thereby leading to a high desire to work given high job life, and that the organizational goal and performance may be raised by continuing an effort for selfdevelopment, but that the low job satisfaction leads inversely to difficulty for nursing in good quality, thereby receiving a negative impact even in the aspect of people's health management [9].

Performance is a concept that is used most frequently in the organization, and that can be interpreted diversely [10]. Work performance implies a level of carrying out the amount of work responsibilities [11]. Hence, nursing performance can be defined as a level of fulfilling nursing task, is available for grasping ability of being possessed by a nurse, and can confirm whether a subject was offered appropriate nursing, thereby being able to evaluate the nursing quality depending on nursing performance level [8][10]. The successful nursing performance is included human relation skills available for providing a safe and effective care to a patient as well as nursing knowledge, clinical judgment ability, and capacity of coping with a stressful situation [10], and is highly relevant to job satisfaction [12]. A factor of affecting the nursing performance was identified to be involved academic background [13][14], outpatientclinic work [13], age [14], clinical career [12][13], professional autonomy [15], empowerment [8][12][15], job satisfaction [13], and the completion of professional curriculum [15].

Accordingly, this study aims to offer grounds for developing a nurse's capacity and enhancing nursing performance through grasping job satisfaction, workplace learning, and nursing performance in nurses who work at general hospital, through confirming a correlation among job satisfaction \& workplace learning and nursing performance, and through identifying a factor that job satisfaction and workplace learning have an impact on nursing performance.

\section{Study design}




\subsection{Study design}

This study confirms job satisfaction, workplace learning, and nursing work performance of nurses. It is also a descriptive research study to identify the relationship between job satisfaction, workplace learning, and nursing performance, and to identify factors that affect nursing performance.

\subsection{Research subjects}

The $\mathrm{G}$ * power statistical program was used to estimate the subjects, minimum sample size was 136, based on 8 independent variables including multiple regression analysis, intermediate effect size .15 , significance level .05 , power of $90 \%$, general characteristics, workplace learning and job satisfaction. In consideration of the dropout rate of 20\%, 165 questionnaires were recorded to nurses working at general hospitals in $\mathrm{C}$ city. Of the questionnaires provided, 158 were collected (95.8\% recovery rate) and 155 were analyzed except for the three poorly answered questionnaires.

\subsection{Data collection methods and ethical consideration}

The data collection period was from October 1, 2016 to October 30, 2016. Before this study was conducted, all researchers completed lectures on research ethics, and the research was reviewed by the Institutional Ethics Review Committee (Approval No. 2016-0002). The data collection was conducted by the researcher who received approval for the questionnaire of the director, visited the nursing department directly, explained the purpose and contents of the study, distributed the structured questionnaires to the nurses who agreed to participate in the research, we gave gift to the person who collected data in return.

\subsection{Data statistics}

The statistical analysis of this study was analyzed using SPSS/Win 20.0 program. The general characteristics of the subjects were frequency, percentage, mean and standard deviation, and the difference between the workplace learning, job satisfaction, and nursing work performance according to the general characteristics of the nurses was tested by t-test, ANOVA and Scheffè test. Pearson's correlation coefficients were calculated to identify correlations among variables of workplace learning, job satisfaction, and nursing work performance. The factors affecting nursing performance were analyzed by Stepwise multiple linear regression.

\section{Research results}

\subsection{Job satisfaction, workplace learning and nursing work performance of the subjects}

In terms of job satisfaction, workplace learning and nursing performance, Job satisfaction was 2.99 on the 5-point scale, in the sub-domain, the maintenance area is 2.59 , the autonomy is 2.94 , the professional level is 3.22 , the work requirement is 2.87 , the interaction area is 3.52 , the doctor-nurse relationship area is 2.86 . The administrative area was 2.90 points, the interaction area was the highest, and the job satisfaction of the pay area was lowest.

Workplace learning was 3.97 points on an average of 6 points. In terms of sub-areas, 3.80 points for formal learning, 4.02 points for informal learning, and 4.08 points for incidental learning. The results of the nursing work were 3.70 points on a 5 point scale. The results of 
the nursing work were 3.70 points on a 5 point scale. In the case of nursing performance, 3.81 points for nursing work performance, 3.73 points for nursing work attitude, 3.60 points for nursing work level improvement, 3.68 points for nursing work performance and the lowest level of nursing work performance [Table 1].

Table 1. The degrees of job satisfaction, workplace learning, and nursing performance

\begin{tabular}{|c|c|c|c|}
\hline Variables & Subcategories & Mean & $\pm \mathrm{SD}$ \\
\hline \multirow{8}{*}{ Job satisfaction } & total (5points) & 2.99 & \pm 0.43 \\
\hline & salary & 2.59 & \pm 0.64 \\
\hline & Autonomy & 2.94 & \pm 0.51 \\
\hline & Professional level & 3.22 & \pm 0.46 \\
\hline & Business requirement & 2.87 & \pm 0.52 \\
\hline & Interaction & 3.52 & \pm 0.63 \\
\hline & Doctor-Nurse Relationship & 2.86 & \pm 0.95 \\
\hline & administration & 2.90 & \pm 0.47 \\
\hline \multirow[t]{4}{*}{ Workplace learning } & total (6points) & 3.97 & \pm 0.80 \\
\hline & Formal learning & 3.80 & \pm 0.91 \\
\hline & Non formal learning & 4.02 & \pm 0.83 \\
\hline & Incidental learning & 4.08 & \pm 0.79 \\
\hline \multirow[t]{5}{*}{ Nursing performance } & total (5points) & 3.70 & \pm 0.48 \\
\hline & Competency & 3.81 & \pm 0.55 \\
\hline & Attitude & 3.73 & \pm 0.50 \\
\hline & Willingness to improve & 3.60 & \pm 0.56 \\
\hline & Application of nursing process & 3.68 & \pm 0.61 \\
\hline
\end{tabular}

\subsection{Job satisfaction, workplace learning, nursing work performance according to general characteristics of subject}

The results of this study are as follows. First, the job satisfaction, workplace learning and nursing work performances were statistically significantly different according to the work department, position, and work type. There were significant differences according to education level, marital status, department of work, and type of work, and there was no significant difference according to general characteristics of workplace learning [Table 2].

\section{Conclusion}

The purpose of this study is to investigate factors that can improve the performance of nursing work in the future. The average job score of the general hospital nurse was 3.97 points for 6 points. The job satisfaction was 2.99 for 5 points and 3.70 points for 5 points. As for the sub-domain, the formal learning of the workplace learning was 3.80 points, the 
informal learning was 4.02 points, and the accidental learning was 4.08 points, and the score of accidental learning was the highest.

Table 2. Differences of job satisfaction, workplace learning, and nursing performance according to general characteristics of subjects

\begin{tabular}{|c|c|c|c|c|c|c|c|c|c|c|c|c|c|c|c|}
\hline \multirow{2}{*}{$\begin{array}{c}\text { Characteristi } \\
\text { cs }\end{array}$} & \multirow{2}{*}{ Categories } & \multicolumn{5}{|c|}{ Job satisfaction } & \multicolumn{4}{|c|}{ Workplace learning } & \multicolumn{5}{|c|}{ Nursing performance } \\
\hline & & M & $\pm \mathrm{SD}$ & & $t$ or $F$ & $p$ & M & $\pm \mathrm{SD}$ & $t$ or $F$ & $p$ & M & $\pm \mathrm{SD}$ & & $t$ or $F$ & $p$ \\
\hline Education & Associate degree & 3.00 & \pm 0.37 & & 0.56 & .571 & 3.85 & \pm 0.72 & 0.55 & .578 & 3.59 & \pm 0.37 & $\mathrm{a}$ & 3.34 & .038 \\
\hline \multirow[t]{2}{*}{ level } & Bachelor degree & 2.96 & \pm 0.42 & & & & 3.98 & \pm 0.80 & & & 3.68 & \pm 0.50 & $\mathrm{a}$ & $(a<b)$ & \\
\hline & $\geq$ Master degree & 3.05 & \pm 0.50 & & & & 4.05 & \pm 0.87 & & & 3.90 & \pm 0.49 & $\mathrm{~b}$ & & \\
\hline \multirow[t]{2}{*}{$\begin{array}{c}\text { Marital } \\
\text { status }\end{array}$} & Single & 2.95 & \pm 0.42 & & -1.41 & .162 & 3.92 & \pm 0.78 & -0.97 & .334 & 3.59 & \pm 0.45 & & -3.71 & $<.001$ \\
\hline & Married & 3.04 & \pm 0.43 & & & & 4.04 & \pm 0.81 & & & 3.87 & \pm 0.48 & & & \\
\hline \multirow[t]{5}{*}{ Religion } & None & 3.03 & \pm 0.41 & & 2.16 & .077 & 4.03 & \pm 0.77 & 0.56 & .691 & 3.75 & \pm 0.45 & & 1.41 & .234 \\
\hline & Buddhism & 3.27 & \pm 0.16 & & & & 4.13 & \pm 0.22 & & & 3.43 & \pm 0.36 & & & \\
\hline & Protestant & 2.91 & \pm 0.44 & & & & 3.80 & \pm 0.80 & & & 3.53 & \pm 0.58 & & & \\
\hline & Catholic & 2.90 & \pm 0.48 & & & & 3.89 & \pm 0.97 & & & 3.72 & \pm 0.53 & & & \\
\hline & Etc. & 2.54 & \pm 0.24 & & & & 3.81 & \pm 0.14 & & & 3.83 & \pm 0.17 & & & \\
\hline Working & General ward & 2.93 & \pm 0.42 & $\mathrm{a}$ & 3.45 & .010 & 3.99 & \pm 0.84 & 1.43 & .228 & 3.66 & \pm 0.55 & $a b$ & 2.67 & .035 \\
\hline \multirow[t]{4}{*}{ department } & $\begin{array}{c}\text { Intensive care } \\
\text { unit }\end{array}$ & 2.91 & \pm 0.32 & $\mathrm{a}$ & $(a<b)$ & & 3.80 & \pm 0.70 & & & 3.59 & \pm 0.41 & $\mathrm{a}$ & $(a<b)$ & \\
\hline & Operation room & 3.08 & \pm 0.30 & $a b$ & & & 3.73 & \pm 0.75 & & & 3.85 & \pm 0.34 & $a b$ & & \\
\hline & Emergency room & 3.30 & \pm 0.55 & $\mathrm{~b}$ & & & 4.27 & \pm 0.59 & & & 3.85 & \pm 0.36 & $a b$ & & \\
\hline & Etc. & 3.06 & \pm 0.46 & $a b$ & & & 4.10 & \pm 0.97 & & & 3.97 & \pm 0.39 & $\mathrm{~b}$ & & \\
\hline \multirow[t]{3}{*}{ Position } & Staff nurse & 2.96 & \pm 0.03 & $\mathrm{a}$ & 5.69 & .004 & 3.94 & \pm 0.80 & 1.76 & .176 & 3.68 & \pm 0.48 & & 2.75 & .067 \\
\hline & Charge nurse & 3.23 & \pm 0.15 & $\mathrm{a}$ & $(a<b)$ & & 4.29 & \pm 0.54 & & & 3.99 & \pm 0.35 & & & \\
\hline & $\begin{array}{c}\text { Head nurse \& } \\
\text { over }\end{array}$ & 3.81 & \pm 0.19 & $\mathrm{~b}$ & & & 4.76 & \pm 0.88 & & & 4.22 & \pm 0.31 & & & \\
\hline \multirow[t]{3}{*}{ Type of duty } & Fixed duty & 3.41 & \pm 0.45 & $\mathrm{a}$ & 4.52 & .012 & 4.50 & \pm 1.21 & 2.40 & .094 & 4.22 & \pm 0.36 & a & 5.81 & .004 \\
\hline & Shift duty & 2.96 & \pm 0.42 & $\mathrm{~b}$ & $(a>b)$ & & 3.96 & \pm 0.77 & & & 3.66 & \pm 0.49 & $\mathrm{~b}$ & $(a>b)$ & \\
\hline & Etc. & 3.03 & \pm 0.34 & $\mathrm{~b}$ & & & 3.76 & \pm 0.66 & & & 3.80 & \pm 0.30 & $\mathrm{~b}$ & & \\
\hline
\end{tabular}

$(N=155)$

There was no difference according to the general characteristics of workplace learning, and there was a statistically significant difference in job satisfaction according to working department and working style, nursing performance was significantly different according to education level, marital status, department of work and type of work. he correlation between the nursing performance and the main variables of the general hospital nurses showed that the higher the age, the higher the work experience, the higher the workplace learning level, the higher the job satisfaction, the higher the performance of the nursing work. The results of this study indicate that the factors affecting the nursing work performance are particularly important in confirming the workplace learning that was lacking in the existing research. 


\section{References}

[1] A.K. Yeung, D.O. Ulrich, S.W. Nason, and M.A.V. Gilnow, "Organizational learning capability: Generating and generalizing ideas with impact," Management Learning, vol.32, no.2, pp.284-286, (1999)

[2] D.B. Kawn, "Comprehensive study on the concept and theory of evolution and human resource development," Seoul; Wonmi, New York, Oxford University Press, (2003)

[3] S.J. Jin and Y.H. Cho, "Hospital workplace learning and innovativeness: The role of perceived clarity of organizational vision as a moderator," Journal of the Korean Data Analysis Society, vol.14, no.3, pp.17151729, (2012)

[4] D. Boud and J. Garrick, "Understanding learning at work," London and New York: Routledge, (1999)

[5] K.E. Watkins and V.J. Marsick, "Towards a theory of informal and incidental learning in organizations," International Journal of Lifelong Education, vol.11, no.4, pp.287-300, (1992)

[6] C.R. Bi and K.E. Lee, "The impact of workplace learning on organizational commitment and career satisfaction in chinese firms," The Journal of Eurasian Studies, vol.11, n.4, pp.21-42, (2014)

[7] E.A. Locke, "Then ature and causes of job satisfaction," M.D. Dunnette, Handbook of industrial and organization psychology, Chicago: RandMcnal, (1976)

[8] M.S. Song, "The relationships between the empowerment, nursing performance, job satisfaction and turnover intention of long-term care hospital nurses," JJKAIS, vol.14, No.5, pp.2304-2314, (2013)

[9] Y.G. Sin, "Approach to management organization act of humanity," Seoul, Dasan, (2005)

[10] Y.K. Ko, T.H. Lee, and J.Y. Lim, "The structural equation modeling on job performance of clinical nurse," Journal of Korean Academy of Nursing, vol. 37, No. 3, pp.286-294, (2007)

[11] M. Wetzels, K. Ruyter, and J. Bloemer, "Antecedents and consequences or role stress of retail sales persons," Journal of Retailing and Consumer Services, vol.7, no.2, pp.65-75, (2000)

[12] J.Y. Choi, E.K. Kim, and S.Y. Kim, "Effects of empowerment and job satisfaction on nursing performance of clinical nurses," Journal of Korean Academy of Nursing Administration, vol.20, no.4, pp.426-436, (2014)

[13] S.M. Wi and Y.J. Yi, "Influence of emotional labor on job satisfaction, intent to leave, and nursing performance of clinical nurses," Journal of Korea Academy of Nursing Administration, vol.18, no.3, pp.310$319,(\mathbf{2 0 1 2})$

[14] G.M. Noh and M.S. Yoo, "Effects of workplace spirituality and organizational citizenship behavior on nursing performance," Journal of Korean Academy of Nursing Administration, vol.22, no.3, pp.251-259, (2016)

[15] A.K. Lee, J.Y. Yeo, S. Jung, and S.S. Byun, "Relations on communication competence, job-stress and jobsatisfaction of clinical nurse," Journal of the Korea Contents Association, vol.13, no.12, (2013) 